\title{
A comunicação como estratégia para a participação do cidadã̃o no estado democrático de direito
}

\author{
Communication as a strategy for the citizen's \\ participation in a democratic rule-of-law state
}

\section{La comunicación como estrategia para la participación del ciudadano en el estado democrático de derecho}

\section{Patrícia Cerqueira Reis}

- Mestre em comunicação pela Escola de Comunicações da Universidade Federal do Rio de Janeiro (ECO-UFRJ)

- Especialista em Análise de Políticas Públicas pelo Instituto de Economia da UFRJ

- Especialista em Administração e Sistemas de Informação pela Universidade Federal Fluminense (Casi-UFF)

- Pesquisadora e professora da Escola Superior de Propaganda e Marketing (ESPM-RJ)

- Consultora em gestão de comunicação e marketing territorial

- Foi supervisora de comunicação do Comitê de Candidatura Rio 2016, coordenadora de comunicação da Associação Nacional da Saúde (ANS) e atuou no marketing do Unibanco, da CCAA e da Golden Cross

- Artigos de sua autoria: Comunicação, cultura e sustentabilidade (e.paper); A gestão da comunicação na sociedade da informação: estudo de caso sobre agência reguladora; TV pública digital: análise da política pública para um espaço midiático interativo, participativo e democrático

•patriciareis@espm.br 
Este artigo propõe analisar a função estratégica que a comunicação, como mecanismo de estímulo ao diálogo e participação, ocupa no modelo constitucional de estado democrático de direito. Por meio de uma pesquisa conceitual nos campos do direito constitucional, da teoria política e da comunicação pública discute-se que o reconhecimento dos diferentes grupos civis organizados, a participação e a pressão desses grupos por seus interesses por meio do lobby na formulação e implementação de políticas públicas fazem parte do modelo democrático adotado no Brasil a partir de 1988.

PALAVRAS-CHAVE: CIDADANIA • DEMOCRATIZAÇÃO • ESTADO DEMOCRÁTICO DE DIREITO • COMUNICAÇÃO • LOBBY

\section{Abstract}

This article proposes to examine the strategic role that communication, as a mechanism for encouragement of dialogue and participation, has in the constitutional model of a democratic rule-of-law state. Through research in the fields of constitutional law, political theory and public communication, one discusses the recognition of different organized civic groups, the participation and pressure of these groups for satisfaction of their interests, through lobbying for development and implementation of public policies are part of the democratic model adopted in Brazil since 1988.

KEYWORDS: CITIZENSHIP • DEMOCRATIZATION • DEMOCRATIC RULE-OF-LAW STATE • COMMUNICATION

\section{Resumen}

Este artículo se propone examinar el papel estratégico que la comunicación, como un mecanismo para fomentar el diálogo y la participación, ocupa en el modelo constitucional de un estado democrático de derecho. A través de una investigación conceptual en los campos del derecho constitucional, de la teoría política y de la comunicación pública, se afirma que el reconocimiento de diferentes grupos cívicos organizados, la participación de estos grupos y la presión en defensa de sus intereses a través del lobby en la formulación e implementación de políticas públicas forman parte del modelo democrático adoptado en Brasil desde 1988.

PALABRAS CLAVE: CIUDADANÍA • DEMOCRACIA • ESTADO DEMOCRÁTICO DE DERECHO • COMUNICACIÓN 
A possibilidade de participação e controle social no processo de formação do estado e o exercício da democracia representativa no Brasil tiveram início no final da década de 1980. A configuração do estado democrático de direito, prevista na Constituição Federal de 1988, representa a terceira geração do direito na construção dos paradigmas do estado. Embora haja a legitimação do coletivo e das responsabilidades de todos sobre o bem público e na construção do espaço público, a prática do exercício da cidadania traz a marca de séculos de dominação econômica, opressão social pelo estado e do poder político das elites.

\section{O ESTADO DEMOCRÁTICO DE DIREITO E UM NOVO MODELO DE ARTICULAÇÃO ENTRE OS SETORES}

\section{A construção do estado democrático de direito}

Para a teocracia hebraica, o estado grego e a república romana, o cidadão só pode desenvolver sua personalidade se estiver plenamente integrado à sociedade política. Em Roma, o veto do tributo da plebe contra ações injustas dos patrícios e a lei de Valério Publícola proibindo penas corporais contra os cidadãos são reconhecidos como os antecedentes formais das declarações de direitos, embora o alcance dessas medidas fosse restrito à classe dominante, excluindo-se desse direito os escravos e as classes economicamente pobres e politicamente sem acesso.

O entusiasmo religioso, vinculado ao poder político vigente, fez com que o individualismo sucumbisse ao poder da Igreja Católica. As ideias sobre o individualismo vão ressurgir anos depois na Revolução Puritana contra o despotismo religioso, levando o povo inglês a formular ideais de liberdade individual na Revolução Gloriosa, em 1688.

Embora Maquiavel tentasse aperfeiçoar a arte de governar, ensinando ao seu príncipe como obter, manter e expandir o poder, através de uma abordagem científica e positiva, para governar no mundo real, os filósofos políticos dos séculos XVII e XVIII basearam suas teorias de estado na natureza humana, no comportamento individual e na relação entre os indivíduos (Carnoy, 1988).

A idéia de estado Moderno surge no século XVIII com a Revolução Americana e a Revolução Francesa, que trazem em si os ideais jusnaturalistas e contratualistas. A primeira, concretiza o pensamento de John Locke (Essay on civil government, 1690), que defende a proteção à propriedade como forma de garantia do direito individual. Já a Revolução Francesa será fundamentada em Jean-Jacques Rousseau (Du contrat social, 1762), que eleva a liberdade a valores supremos, desde que criada e garantida pela vontade geral, e em Charles Montesquieu (L'esprit des lois, 1748), que acredita na separação dos poderes para alcançar a liberdade no poder político ao limitar-se reciprocamente. Essas duas revoluções irão inserir as garantias aos direitos fundamentais como essência do estado Moderno. 
A Declaração dos Direitos do Homem e do Cidadão (1789), que tem como características fundamentais o intelectualismo, o mundialismo e o individualismo, torna-se o documento mais marcante do estado liberal de direito. Os direitos individuais vão disseminar-se pela Europa, fundamentando o estado uno, indivisível em três poderes (legislativo, executivo e judiciário) e nãointervencionista. É ao estado que se outorga o uso legítimo da força, segundo Max Weber. Nesse momento, as relações entre os indivíduos e o estado se dão pela oposição dos direitos. A declaração traz o direito do homem, de caráter pré-social, independentemente de sua integração em uma sociedade política, e relaciona-se à liberdade, à propriedade e à segurança. $\mathrm{O}$ direito do cidadão, enquanto participante de uma sociedade política, restringe-se apenas às liberdades políticas do indivíduo.

Adam Smith (The wealth of nations, 1776) estabelece uma forte justificativa econômica (melhorar sua condição e aumentar seus bens) para a prevalência do individualismo e, principalmente, agrega a ideia de que, ao agir em busca de seu próprio interesse econômico, o indivíduo maximiza o bem-estar coletivo. Para ele, o papel do estado torna-se periférico em relação à dinâmica social fundamental. A ideia de que a sociedade é regulada pela "mão invisível" do mercado é uma das principais referências da sua teoria.

O desenvolvimento industrial e a formação da classe operária demonstraram que os direitos individuais não eram suficientes para garantir proteção contra a opressão que se configurava política e economicamente.

Stuart Mill, na segunda metade do século XIX, reconhece no processo democrático uma forma de contribuição ao desenvolvimento humano e um guia para o alcance de uma sociedade livre e equitativa. Para ele as desigualdades não são inerentes ao capitalismo, mas acidentais e podem ser remediadas. Reconhece também as clivagens sociais e defende a educação como o elemento propulsor da civilização, assim como identifica o analfabetismo, a dependência da ajuda financeira do estado, a inadimplência de impostos e a situação de falência como os obstáculos à expansão do sufrágio universal.

Os principais documentos de crítica ao regime liberal foram o Manifesto Comunista (Marx, 1848), a Constituição Mexicana (1917) e a Constituição de Weimar (1919). Juntos com a Revolução Mexicana e a Revolução Bolchevista, inserem os direitos sociais e econômicos ao lado dos direitos individuais e modulam o segundo paradigma do direito: o estado social de direito.

Com o início da Segunda Guerra Mundial (1939), a Constituição de Weimar não chega a ser implementada, mas irá, por conta de uma interpretação errônea da teoria positivista de Hans Kelsen, identificada como uma Grundnorm (aquela que não se relaciona com ou se submete a nenhuma outra lei), dar fundamento legal às ações de Adolf Hittler. 
Somente após o término da Segunda Guerra Mundial é que os fundamentos do estado social de direito serão aplicados. Em 1945, vinte e um representantes de diferentes países se reúnem no México e firmam como primeiro objetivo da Organização das Nações Unidas (cuja estrutura foi criada por Kelsen) a redação da Declaração Universal dos Direitos Humanos (1948). Esta consagra a certeza dos direitos por sua prévia e clara fixação; a segurança dos direitos pela existência de normas que garantam que eles serão respeitados e a possibilidade dos direitos exigindo a existência de instrumentos necessários ao gozo disponível para todos os indivíduos (Dallari, 1972, p. 185).

O estado social de direito adiciona os direitos sociais aos direitos individuais do estado liberal de direito e torna o estado um prestador de serviços à coletividade. Ou seja, o estado nesse momento é visto como um ente que trabalha para o coletivo.

No Brasil, a Constituição Brasileira de 1946 (era Vargas), embora impregnada da doutrina fascista (totalitarismo desenvolvido por Benito Mussolini na Itália), traz em si os princípios do estado social de direito. O estado brasileiro assume uma posição paternalista ou clientelista, prestador de serviços à sociedade, caracterizando-se pela cooptação das instituições sociais. Torna-se um estado que concede garantias para a sobrevivência e o incremente do consumo do trabalhador como: fundo de garantia por tempo de serviço, carteira de trabalho, facilidades para compra da casa própria, saúde pública, entre outros. O trabalho formal, "de carteira assinada" prevalece sobre as iniciativas individuais ou empreendedoras, uma vez que o acesso aos benefícios ocorria de forma comprobatória pela carteira de trabalho.

O modelo ocidental divide-se, então, por um lado, com a democracia liberal caracterizada pela concorrência econômica e um estado que intervém pouco na economia e, por outro lado, com a tecnodemocracia caracterizada por grandes empresas estatais, assegurando o governo o controle geral da produção de forma intervencionista. O fim ou a derrocada do comunismo e a necessidade de reestruturação da sociedade de consumo, a escassez de recursos, a crise do petróleo e a queda da produção, o aumento considerável do desemprego e, consequentemente, a redução do consumo levam ao esgotamento do estado de bem-estar nos anos 1980 (chamados por alguns economistas de década perdida para a América Latina).

Margareth Thatcher, na Inglaterra e Ronald Reagan, nos Estados Unidos, afirmam o esgotamento do estado e propõem a criação do estado liberal, caracterizado pelo estado mínimo, não-intervencionista, mas mantenedor de condições de equilíbrio econômico e financeiro para a atuação dos fluxos de mercado. Na Europa, teóricos que se referenciavam nos ideais da Revolução Francesa e do contato social de Rousseau, criticam o estado liberal e propõem o modelo do estado democrático de direito. 
No Brasil, após o período da ditadura militar (1964-1985), uma máquina administrativa inchada e extremamente burocrática reforça a ineficiência do modelo desenvolvimentista, da prestação de serviço centralizada no estado e do corporativismo de elite. A Constituição de 1988 torna-se, então, um marco de mudanças estruturais na forma de relacionamento entre cidadão e o estado. Seu texto junta conceitos das teorias liberais e democráticas de direito, a linha norte-americana e a europeia. Porém seus princípios fundamentais (fonte do direito que se irradia para todas as normas) estão baseados no paradigma do estado democrático de direito (do art. $1^{\circ}$ ao $4^{\circ}$ ), reforçado pela explicitação dos direitos e deveres individuais e coletivos $\left(\right.$ art. $5^{\circ}$ ) e dos direitos sociais $\left(\right.$ do art. $6^{\circ}$ ao $11^{\circ}$ ). A Constituição insere assim a terceira geração de direitos: os direitos difusos e de cidadania.

Entende-se como direito difuso aquele que pertence a todos. As ações de direito difuso não têm titularidade e seus resultados beneficiam o coletivo, como, por exemplo, as ações de defesa do clima e do meio ambiente. Já o direito de cidadania corresponde ao direito adquirido por todo cidadão de participar da ordenação do estado de forma ampliada, não se restringindo apenas ao sufrágio direto ou indireto. O Estatuto da Criança e do Adolescente e o Código de Defesa do Consumidor trazem princípios de direitos de cidadania.

O estado democrático de direito estabelece uma nova forma de relação entre indivíduos e o estado. Não há mais uma posição oponível - o indivíduo não se posiciona a favor ou contra o estado como no estado liberal, nem há ações de defesa do direito do indivíduo contra o estado. A relação também não é mais de prestação de serviços, ou seja, deixa de existir a exclusividade do estado na prestação de serviços ao cidadão. Nesse modelo, a participação de grupos sociais organizados no processo de governo se insere nos deveres de cidadania. O cidadão não é um cliente à espera do que o estado pode fazer por ele e, sim, um coparticipante do processo.

A Constituição de 1988 instala a difusão do conceito de democracia. A partir de meados da década de 1990, esse conceito amplia-se para a compreensão da dimensão da democracia participativa.

\section{Mudanças nas relações entre o público e o privado}

Como consequência da implantação do modelo de estado democrático de direito pela Constituição de 1988, novas formas de relacionamento e de compreensão do espaço público e privado são instituídas. Amplia-se o conceito de público para além da responsabilidade do governo e compreende-se que o bem público é aquele que influência a vida de todos e traz em si as ideias de coletivo, interesse público e bem de todos, seja material ou social. 
Para Held (1989), a ordem política se alcança por uma complexa rede de interdependências entre a ordem política, econômica, as instituições sociais e as atividades que dividem os centros de poder, sendo essas últimas criadoras de múltiplas pressões às quais se deve ceder. O poder do estado é um aspecto central dessas estruturas, não se constituindo em sua única variável (Batista, 2002, p. 3).

Neste contexto, o processo de democratização está se estendendo da esfera política, onde o indivíduo é reconhecido apenas no seu papel de cidadão, para a esfera social, onde ele deve ser considerado nos seus múltiplos papéis e identidades, como pai, empresário, trabalhador, estudante etc. Esse processo se traduz na passagem da democracia representativa para a democracia social. Esta não deve ser entendida como um novo modelo, mas como o reconhecimento de que espaços antes preenchidos pelas organizações burocráticas e hierarquias governamentais passam a ser ocupados por organizações sociais. O estado é chamado a ocupar um novo papel e a visão desse ambiente se desloca para a sociedade civil, o que nos leva a considerar que existem outros centros de poder, caracterizados pelo pluralismo político.

Um marco da alteração das relações nos espaços públicos e privados se deu com a reforma do estado iniciada na década de 1990 e descrita por Bresser Pereira (2007). Com a reforma, o estado deixa de ser um ator produtivo, um prestador de serviços, característica do estado social de direito, para tornar-se gestor, regulador, provedor e promotor dos interesses públicos.

A redução do estado se deu por diferentes vias: (a) privatização - transformação de empresas estatais em privadas; (b) publicização - transformação de organizações estatais em organizações de direito privado (são instituições públicas não-estatais que ficam responsáveis pela execução de atividades que não são mais consideradas como exclusivas do estado; têm um caráter público, mas são entidades de direito privado, o que lhes confere autonomia administrativa e financeira); e (c) terceirização - transferência dos serviços auxiliares ou de apoio para o setor privado.

O capitalismo contemporâneo configura-se, então, por três modalidades de propriedade: (a) propriedade privada - voltada para o lucro e consumo privado; (b) propriedade estatal - subordinada ao governo e formada por um quadro de funcionários públicos concursados (herdeiros da gestão burocrática de Weber); e (c) propriedade pública não-estatal - formada por pessoas jurídicas de direito privado - ONGs, OSCIPs, fundações, movimentos sociais, instituições filantrópicas e associações civis - e por pessoas jurídicas de direito público - fundações públicas, autarquias e organizações sociais (Bresser-Pereira, 2007). 
$\begin{array}{ll}\begin{array}{c}\text { Primeiro setor } \\ \text { (governo) }\end{array} & \begin{array}{l}\text { Transferência de suas funções }=> \\ \text { Estado mínimo gestor }\end{array} \\ & \end{array}$

Terceiro setor

4
Segundo setor (empresas privadas)

Braço social das empresas

Fonte: infográfico ilustrativo desenvolvido pela autora

O modelo de reforma adotado nos anos 1990 reconfigurou o ambiente institucional a partir de mudanças estruturais na política econômica, dirigida ao redimensionamento do estado e à abertura da economia ao exterior; do posicionamento do poder executivo como mediador estratégico materializado na política regulatória; da obrigatoriedade à filiação dos atores organizados como parâmetro de atuação dos seus interesses, de caráter voluntário e coletivo (em substituição ao antigo corporativismo e ao monopólio da representação). Esta última instância caracteriza-se pelo surgimento de novos tipos de entidades com mais abrangência e mobilidade de atuação e pela adaptação das antigas estruturas oficiais e das associações independentes a um novo contexto. Observa-se também a intensificação das ações de lobby, que passam a ser reconhecidas de forma legítima como mecanismo de participação dos grupos privados organizados com base em seus interesses quanto a questões de interesse geral (Boschi, 2002).

Figura 2 - Modelo de participação no estado democrático de direito

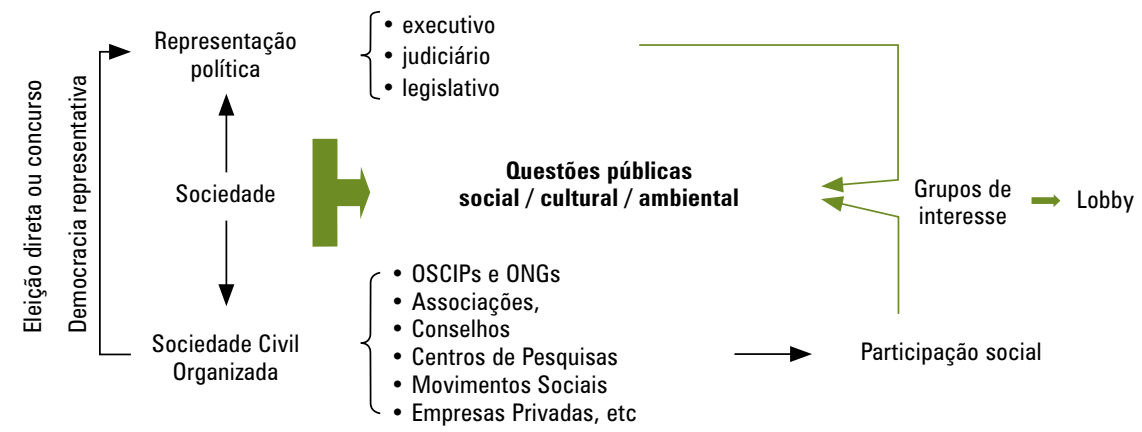

Fonte: infográfico ilustrativo desenvolvido pela autora 
Na dimensão política, o estado democrático de direito se caracterizará pela criação de mecanismos de acompanhamento social das questões públicas, como as audiências públicas, o plano diretor e o orçamento participativo. A divisão de poderes - legislativo, executivo e judiciário - deixa de estar centralizado na representação política e se divide pela sociedade civil organizada. A institucionalização do lobby legitima a pressão dos diferentes grupos sociais, levando à redução dos mandatos imperativos (típicos da democracia representativa) nos quais há a prevalência dos interesses dos grupos que financiam as campanhas sobre o interesse dos demais grupos sociais envolvidos com a questão em pauta. As mudanças trazem ainda modelos de participação, como plebiscitos (quando o que se escolhe é uma matéria em questão), referendos (nos quais se vota o texto de uma lei) e ações populares (que correspondem ao exercício da cidadania direta, podendo qualquer cidadão mover uma ação popular por danos ao erário, ao meio ambiente, ao patrimônio histórico ou por moralidade).

\section{A cidadania ativa}

A soberania popular pode ocorrer: pela democracia direta, a qual pressupõe que o povo, reunido em assembleia, toma decisões diretas sobre as políticas que lhe dizem respeito; pela democracia semidireta, que utiliza técnicas de intervenção do povo nas decisões do estado; ou pela democracia indireta, compreendendo a eleição de representantes, a qual pode se dar pela "monarquia eletiva" (denominação francesa), cujo chefe de estado é eleito pelo sufrágio universal (Brasil, Estados Unidos e França) ou pela "oligarquia eletiva”, em que a classe política é formada pelos parlamentares (Inglaterra) (Batista, 2002).

Noberto Bobbio (1986) conclui que, quanto maior a democracia, mais se exige que a democracia representativa seja substituída pela democracia direta, sem, contudo, entender esta última como a participação de todos os cidadãos em todas as decisões relacionadas com eles, o que reduziria, fatalmente, todos os interesses humanos ao interesses da pólis, acarretando a completa eliminação da esfera privada na esfera pública (Batista, 2002, p. 3).

Busca-se então um modelo de participação que minimize as deficiências da representatividade, impeça a existência de mandatos imperativos, mas reconheça e incentive a participação do individuo, organizado socialmente, nas diversas esferas em que ele está inserido.

Tal ideal nos remete ao conceito de cidadania moderna, que traz um forte vínculo com a dinâmica política, na qual o cidadão é reconhecido como membro completo de uma sociedade de iguais. Para isso, torna-se necessário que os indivíduos tenham cada vez mais acesso aos direitos de cidadania - civis, políticos e sociais - previstos no paradigma do estado democrático de direito. Porém, a estrutura democrática com a qual nos confrontamos é frágil e a sim- 
ples aquisição destes direitos não garante uma sociedade política igualitária ou estável. Surge então o conceito de cidadania ativa.

A cidadania ativa está diretamente relacionada com o grau de participação do indivíduo na sociedade de que faz parte e que vai além da simples ideia de representação democrática, levando a que cada indivíduo, para ser considerado cidadão, tenha que assumir diretamente a responsabilidade de eleger não apenas um representante, mas sua própria condição, afirmando-se a legitimidade democrática para além do voto e do modo de escrutínio, uma legitimidade baseada na própria resposta dada aos anseios sociais (Batista, 2002, p. 10).

Para Batista, são componentes do conceito de cidadania ativa as dimensões da posse de direitos e do exercício de responsabilidades cidadãs. Ao analisar o conceito sob a ótica dessas dimensões, não devemos confundi-las ou superestimar um aspecto em relação ao outro. Tal erro pode fundamentar os governantes em justificativas para a ausência de garantias, sob alegação de que os cidadãos não estão preparados para participar ou de que não assumem seus deveres com a comunidade. Ou, até mesmo, pode propiciar que se estipulem níveis distintos de cidadania pelo grau de participação ou de necessidades (negros, mulheres, indígenas e outras minorias), o que retira o seu caráter igualitário.

Correntes mais progressistas sustentam que os indivíduos só exercem sua cidadania, como membros completos da vida social, se tiverem suas necessidades básicas atendidas. Tal pressuposto remete ao reconhecimento de que as políticas sociais tendem a promover o clientelismo e a prestação de serviço por parte do estado, recolocando-o no formato do estado social de direito.

O uso integrado de todos os mecanismos de exercício da cidadania ativa deve ter como eixo central a capacidade de questionar, avaliar e interferir no desempenho daqueles que exercem cargos públicos e de envolver a sociedade no debate público. Para isso, o pleno direito à informação e o acesso aos mecanismos de participação são condições primordiais. Isso coloca a comunicação das instituições públicas em um patamar estratégico.

\section{0 consumidor cidadão}

Percebida até o fim do século passado como forma de diferenciação social, a posse de bens e serviços, segundo Thorstein Veblen (1983) serve para identificar a posição ocupada pelo indivíduo na hierarquia social, uma vez que se insere na lógica da propriedade individual e da predominância das atividades industriais.

No final dos anos 1990 e início da década de 2000, com o aumento da conscientização sobre questões públicas como meio ambiente, direitos humanos, segurança, entre tantas outras, o poder exercido pelo consumidor passa a ocupar a dimensão do exercício de cidadania. A diferenciação do indivíduo em seus grupos vai, ago- 
ra, além do acúmulo de bens. Autores como Néstor García Canclini (2005), Jesús Martín-Barbero (2002), Manuel Castells (1999) e Pierre Lévy (2002) consideram que o exercício da cidadania também se manifesta na forma como o indivíduo consome produtos, serviços, bens simbólicos, culturais, entretenimento etc.

Para García Canclini (2005), o exercício da cidadania não se limita a questões políticas. São as práticas sociais e culturais que irão dar sentido de pertencimento e de identidade a cada indivíduo. O consumo não é interpretado como algo irracional, suntuoso e supérfluo. Na modernidade, ele é entendido como algo que sustenta, nutre e, até certo ponto, constrói uma nova maneira de ser cidadão. $\mathrm{O}$ exercício ocorre pela interação entre grupos sociais, instituições públicas e empresas privadas, levando o consumidor a assumir uma posição de coprodutor do que será consumido.

A coprodução vai ocorrer pelo aumento da compreensão do consumidor sobre os processos produtivos e, consequentemente, os impactos positivos e negativos que eles causam na sociedade, levando à ocorrência de novas demandas de produtos e modelos de prestação de serviços.

Surge a ideia de "empoderamento" do consumidor, tradução para o português do termo empowerment, que consiste na tomada para si do poder. Trata-se de um poder que nasce a partir do conhecimento sobre os processos de produção e consumo. Esse poder que passa para as mãos do consumidor é ampliado pelas tecnologias de informação e comunicação, pelo incremento da internet e das redes sociais, transformando a sua experiência de interferência em informações estratégicas disponíveis para as instituições públicas e empresas privadas repensarem seus modelos de atuação.

\section{AS PRÁTICAS COMUNICATIVAS DAS INSTITUIÇÕES PÚBLICAS E PRIVADAS}

A comunicação contemporânea, seja de instituições públicas ou privadas, ocorre fortemente apoiada nos conceitos de mecanismos de participação e lobby, de cidadania ativa e de "empoderamento" do consumidor.

Na dimensão das instituições privadas, a comunicação de marketing, ou seja, aquela voltada para produtos e serviços com ênfase em geração de negócios, demanda a articulação com questões e exigências sociais,. Deve-se prestar contas sobre processos de produção, dar visibilidade às ações de gestão de impactos, definir canais de comunicação para o pós-venda, criar mecanismos de relacionamento com as cadeias de fornecedores e acompanhar as dinâmicas comunicacionais de consumidores e formadores de opinião nas redes sociais.

Já a dimensão da comunicação institucional precisa vincular a imagem das organizações às questões sociais, para de fato agregar valor à sua marca, criar 
reputação corporativa e, dessa forma, fortalecer o processo de escolha de produtos e serviços. Além disso, é necessário que as organizações se articulem com seus diferentes públicos, estimulando o diálogo e a participação no modelo de negócio. Há que se incluir aqui os grupos sociais organizados, que representem, de forma permanente ou temporária, seus interesses nos processos de formulação e implementação de políticas públicas.

$\mathrm{Na}$ dimensão das instituições públicas não-estatais, ou terceiro setor, a prevalência da comunicação institucional ocorre naturalmente por conta de seu modelo e espaço de atuação. Cabe a essa dimensão comunicacional estimular o exercício da cidadania, dar acesso a informação e educação sobre questões públicas e estimular a mobilização e participação dos grupos sociais organizados.

Por fim, é na dimensão das instituições públicas estatais que a prática comunicativa, como mecanismo de exercício de cidadania, acesso à informação, democratização e participação dos processos de problematização e de decisão sobre as políticas públicas se torna prioritária para a implementação do estado democrático de direito.

Para Pierre Zèmor, a comunicação pública só se legitima com a legitimação do interesse geral. Por isso ela corresponde àquela que ocorre nos espaços púbicos, sob o olhar do cidadão. Seguindo essa lógica, sua finalidade não pode estar desassociada das finalidades das instituições públicas, que são: informar - dar conhecimento e prestar contas; ouvir as demandas, expectativas e interrogações; promover o debate público; assegurar as relações sociais no sentido de pertencimento; e acompanhar as mudanças comportamentais e da organização social.

Zèmor identifica a informação como o objetivo principal das estratégias de abordagem da comunicação de instituições públicas, que podem ser descritas como: (1) responder à obrigação que as instituições públicas têm de informar o público; (2) estabelecer uma relação de diálogo, de forma a permitir a prestação de serviço ao público; (3) apresentar e promover os serviços da administração; (4) tornar conhecida a instituição por meio da comunicação externa e interna; e (5) divulgar ações de comunicação cívica e de interesse geral.

Segundo Monteiro (2007), o processo comunicativo entre estado, governo e sociedade tem o objetivo de informar para a construção da cidadania, uma vez que esse é o caminho para se restabelecer a simetria de poderes na sociedade democrática, dando mais espaço na mídia para as diferentes vozes e gerindo espaços alternativos fora da mídia que permitam a formulação de novas interpretações.

Ana Lúcia Novelli (2006) utiliza os conceitos de Bauman sobre liquidez, leveza e inconstância do ambiente contemporâneo para explicar as novas exigências do consumidor cidadão por transparência, agilidade, eficiência e profissiona- 
lismo e que suscitam diferentes modelos de cidadania, de representatividade e de participação. Todo esse processo de transformação implica utilizar diversos instrumentos de comunicação para a atuação direta ou indireta do cidadão que pode ser informado, consultado, deliberado, regulado ou agente executor. Com isso, a comunicação passa a ser compreendida como estratégia de informação, consulta e participação ativa (fóruns, conselhos, plebiscitos, referendos, audiências públicas, pesquisas de opinião, contratos de cogestão com entidades do terceiro setor etc). Múltiplos mecanismos são adotados na tentativa de ampliar a capacidade de gestão (governança), de articulação e de legitimação (governabilidade). Assim, diferentes princípios ou premissas acabam por serem desenvolvidos para que haja uma efetiva mobilização social e intercâmbio entre os atores sociais dos três setores.

\section{CONSIDERAÇÕES FINAIS}

O modelo de estado democrático de direito instaurado com a Constituição Federal de 1988 dá início, na sociedade brasileira, à compreensão sobre a importância da participação em grupos sociais organizados, da cidadania ativa e do consumo cidadão. Tais mudanças, somadas às transformações provocadas pelas novas tecnologias de informação e comunicação, ao incremento da internet e das redes sociais, exigem uma reflexão sobre a prática comunicacional das instituições públicas e privadas, colocando-a em um patamar estratégico.

As instituições privadas precisam rever seus modelos de negócios e a forma de comunicá-los, estimular a participação dos grupos sociais de interesse delas (stakeholders) e acompanhar as demandas e manifestações dos grupos sociais que de alguma forma possa impactar seu negócio (ampliação do conceito de stakeholders).

Instituições públicas não-estatais, criadas exatamente a partir do modelo de estado democrátrco de direito, possuem mecanismos comunicacionais em consonância com as exigências sociais do estado brasileiro. Cabe a elas se fortalecerem dentro dos setores em que estão inseridas, para de fato serem representativas no processo de problematização, formulação e implementação das políticas públicas das suas áreas de interesse.

É na dimensão das instituições públicas estatais que a compreensão da comunicação como elemento estratégico para a democratização, o exercício da cidadania e o acesso à informação se torna primordial. Ancorada no debate sobre o conceito de comunicação pública, sua prática deve ir muito além da comunicação política. Deve ser pensada na dimensão institucional, como forma de fortalecimento da marca Brasil, inclusive no exterior; na dimensão governamental como prestadora de contas dos governos e como estimuladora para participação no processo de formulação da política pública; e na criação de canais de comunicação que estimulem o diálogo. 
Assim, a comunicação com foco em questões públicas, estratégica para todos os modelos de instituições e organizações sociais, pode ser considerada um dos pilares mais importantes na construção do modelo de estado que escolhemos constitucionalmente. Seu fortalecimento acadêmico e nas práticas organizacionais representam nosso exercício democrático diário.

\section{REFERENCIAS}

BATISTA, Vanessa Oliveira. As declarações de direitos. Revista da Faculdade de Direito da UFMG, Belo Horizonte, n. 36, 1999a.

Efetivação dos direitos humanos. Revista da Faculdade Mineira de Direito, Belo Horizonte, n. 2, 1999b.

Legitimidade e representação democrática. Revista de Direito Comparado, Belo Horizonte, n. 4, 2002.

BOSCHI, Renato; LIMA, M. Regina S. de. 0 executivo e a constituição do estado no Brasil. In: VIANNA, L. Werneck (Org.). $A$ democracia e os três poderes no Brasil. Belo Horizonte: Ed UFMG, 2002.

BRESSER-PEREIRA, Luiz Carlos. A reforma do estado dos anos 90: lógica e mecanismos de controle. Disponível em: <www. bresserpereira.ecn.br>. Acesso em: 20 out. 2007.

CARNOY, Martin. estado e teoria política. Campinas: Papirus, 1988.

CASTELLS, Manuel. A sociedade em rede. Vol. 1 - Era da informação: economia, sociedade e cultura. 4. ed. São Paulo: Editora Paz e Terra, 1999.

COBB, R.; ELDER, C. Issue creation and agenda building. In: ANDERSON, J. E. (Ed.). Cases in public policy making. New York: Praeger, 1976.

DALLARI, Dalmo de Abreu. Elementos de teoria geral do estado. São Paulo: Saraiva, 1972.

GARCÍA CANCLINI, Néstor Consumidores e cidadãos: conflitos multiculturais da globalização. 5. ed. Rio de Janeiro: Editora UFRJ, 2005.

HELD, David. Political theory and the morden state. [Stanford University Press, 1989]. In: BATISTA, Vanessa Oliveira. Legitimidade e representação democrática. Revista de Direito Comparado, Belo Horizonte, n. 4., 2002.

LÉVY, Pierre. Ciberdemocracia. Lisboa: Editions Odile Jacob. 2002.

MARTÍN-BARBERO, Jesús. Chaves do debate: televisão pública, televisão cultural, entre a renovação e a invenção. In: RINCÓN, Omar (Org.). Televisão pública: do consumidor ao cidadão. São Paulo: Friedrich Ebert Stiftung, 2002. p. 41-79.

MONTEIRO, Graça França. A singularidade da comunicação pública In: DURTE, Jorge (Org.). Comunicação pública: estado, mercado, sociedade e interesse público. São Paulo: Atlas, 2007.

NOVELLI, Ana Lúcia C. R. 0 papel institucional da comunicação pública para o sucesso da governança. Organicom - Revista Brasileira de Comunicação Organizacional e Relações Públicas, São Paulo, Gestcorp/ECA-USP, a. 3, n. 4, p. 75- 9, $1^{\circ}$ sem. 2006.

VEBLEN, T. B. A teoria da classe ociosa: um estudo econômico das instituições. São Paulo: Abril Cultural, 1983.

ZÉMOR, Pierre. La communication publique. Paris: PUF, 1995.

Recebido em: 21.01.2011 / Aceito em: 07.06.2011 